\title{
EL GRITO DE LOS BIENES COMUNES: ¿QUÉ SON? Y ¿QUÉ NOS APORTAN? ${ }^{\text {I }}$
}

\section{THE YELL OF THE COMMONS: WHAT IS IT? AND WHAT DOES IT PROVIDE US?}

\author{
Ana Lucía Gutiérrez Espeleta* \\ Flavio Mora Moraga*
}

\section{RESUMEN}

En este artículo se presenta una revisión bibliográfica acerca del debate de los bienes comunes, el cual en las últimas décadas ha tomado fuerza como una vía alterna al análisis de los conflictos provocados por la apropiación de los recursos comunes de la sociedad y por lo tanto, de la humanidad. El neoliberalismo, como modelo de producción dominante en tanto discurso y práctica político económico en nuestras sociedades, ha provocado el enclaustramiento y mercantilización de los recursos naturales.

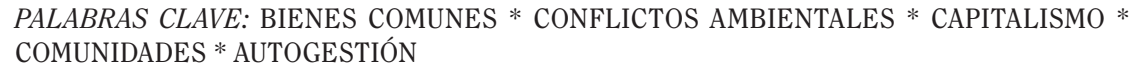

\section{ABSTRACT}

This paper presents a literature review on the debate of the commons, which in recent decades has increased as a viable alternative to the analysis of conflicts caused by the appropriation of common-pool resources of society and therefore of humanity. Neoliberalism, as the dominant production model, involved both in political discourses and economical practices in our societies has led the enclosure and commodification of natural resources.

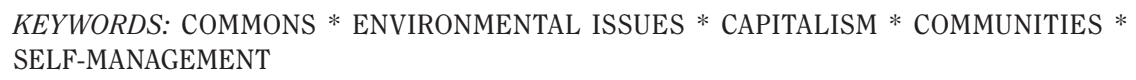

1 Un borrador de este artículo fue discutido en el Programa Nuevas Formas de Acumulación, Distribución y Desigualdad del Instituto de Investigaciones Sociales (IIS) de la Universidad de Costa Rica, el 30 de octubre de 2010; asimismo, el viernes 1 de octubre de ese año, en el marco de las VI Jornadas de Investigación del IIS. Muchísimas gracias a todas y todos los que nos retroalimentaron con sus valiosas observaciones y comentarios. Instituto de Investigaciones Sociales (IIS). ana.gutierrez@ucr.ac.cr

** Cursa la Licenciatura en Ciencias Políticas, Universidad de Cosa Rica (UCR). jf2m013@gmail.com 


\section{INTRODUCCIÓN}

El presente artículo responde a las conclusiones que surgieron en el marco del estudio de los bienes comunes que se realizó en el Programa del Instituto de Investigaciones Sociales de la Universidad de Costa Rica llamado "Nuevas Formas de Acumulación, Distribución y Desigualdad", durante el año 2009. En este espacio se planteó la necesidad de realizar una revisión bibliográfica sobre el tema.

En los siguientes apartados se tratará de reflejar el debate teórico acerca de la definición de bienes comunes, sus características y qué nos aportan para una reflexión final sobre bienes comunes y conflictos socioambientales, precisamente la aplicabilidad y utilidad política en nuestra realidad costarricense. Valga la aclaración, que no se pretende en este artículo realizar un análisis de los conflictos socioambientales en Costa Rica a la luz de los bienes comunes, se considera que para esto, es necesario primero profundizar en el enfoque de bienes comunes; sin embargo, este esfuerzo si puede permitir plantear preguntas que perfilen futuros estudios sobre conflictos socioambientales $y$ bienes comunes.

\section{¿QUÉ SON LOS BIENES COMUNES?}

Al revisar exhaustivamente el debate sobre "bienes comunes", se encuentra una discusión no concluida por parte de los distintos académicos. Con lo anterior, se quiere señalar que se habla de un concepto en permanente construcción, deconstrucción y reconstrucción.

Uno de los esfuerzos por debatir sobre este tema es la conferencia internacional interdisciplinaria sobre "Bienes Comunes y Ciudadanía", realizada en la Ciudad de México en diciembre de 2006, la cual fue convocada por la Oficina Regional Centroamérica, México y Cuba de la Heinrich Böll Stiftung. A esta acudieron representantes de organizaciones sociales, académicas y políticas de 16 países. Los dos objetivos fundamentales de este encuentro fueron debatir sobre algunos aspectos conceptuales e ir preparando el ambiente para la construcción de un consenso sobre una denominación apropiada. Asimismo, se dieron a la tarea de ahondar en la pregunta acerca de si "las ideas maravillosas sobre los commons tenían alguna aplicación y utilidad política en las realidades latinoamericanas" (Helfrich, 2008: 44).

No se ha logrado un total acuerdo en cómo traducir del inglés la palabra commons a un concepto en español que refleje de la mejor manera la idea o la esencia de este término. Esta dificultad lo que revela, es que más allá de un problema de traducción, se está hablando de entender ambigüedades conceptuales $y$ visiones políticas diferentes.

El origen inmediato del término commons remite al famoso ensayo del biólogo estadounidense Garret Hardin, publicado en 1968, como The Tragedy of the Commons (La tragedia de los comunes), el cual apunta al cercamiento que, desde 1740, eliminó los derechos de los campesinos a cultivar, pastorear y cazar en las tierras de propiedad de la nobleza, en Inglaterra y Gales. Este ensayo sirvió de fundamento filosófico y político al sector privado, porque Hardin argumentaba que si nadie era propietario de los ámbitos comunes, "muy pronto serían saqueados, ya que nadie se haría responsable de ellos. Utilizó este argumento para fundamentar la privatización de la propiedad comunitaria" (Barlow, 2008: 4).

Hardin sostenía que un recurso compartido necesariamente se arruinaría, por ello la metáfora de la tragedia. Él trata de demostrar esto, con el ejemplo del pastizal y el ganado, donde cualquiera puede llevar a pastar al ganado sin restricciones, que la libertad de los bienes comunes determina la ruina para todos, por lo que no deben de existir, sino que deben privatizarse, legislarse y ser apropiados por quienes lo gestionen $y$ distribuyan.

A partir del planteamiento de Hardin, se abre el portillo para establecer los derechos de propiedad privada y sustentar que el libre mercado decida cómo lo usará. Siguiendo con esta lógica, solo los propietarios privados tendrán los incentivos necesarios para cuidar la tierra $y$ hacer en ella inversiones valiosas. Ni los gobiernos ni las personas cuentan con los incentivos y las capacidades adecuadas para administrar los recursos humanos de una manera competente. 
Hay autores que plantean que lo señalado por Hardin no es un bien común, sino un régimen de acceso abierto no regulado, una tierra de nadie. Mientras que los bienes comunes se sostienen en un sistema de autogestión $y$ derechos de consenso para controlar el acceso a un recurso y su utilización. En otras palabras, los bienes comunes, tienen límites bien definidos, están sometidos a reglas comprendidas por sus participantes. La gente que participa en un bien común, tiene una comprensión social compartida de quién tiene derecho de usar los recursos y en qué condiciones, en este sentido, bien común es una forma de propiedad y si se construyen las estructuras adecuadas, no tiene porque terminar necesariamente en una "tragedia".

Lo cierto es que Hardin y su tragedia de los comunes, propulsaron la verdadera tragedia que es la del mercado, porque es:

... el mercado el que usa sin cesar muchos de nuestros preciados dones de la naturaleza y deja contaminación y residuos por doquier, sin ni siquiera contabilizar con precisión, desde el punto de vista económico, los costos reales. El problema con la economía convencional es que con demasiada frecuencia no reconoce el valor que los bienes comunes aportan a la actividad de los "mercados" (Bollier, 2008: 35).

Las lógicas que rigen a los bienes comunes y al mercado son muy distintas. Por ejemplo, los bienes comunes ofrecen formas de administración de la propiedad más equitativa que la propiedad privada. Los bienes comunes buscan la sustentabilidad del recurso a largo plazo, mientras que el mercado lo que busca es maximizar beneficios (financieros) a corto plazo. Los tomadores de decisiones, los líderes de algunas potencias, las instituciones comerciales $y$ financieras internacionales $y$ las empresas transnacionales, ven los bienes comunes como una mercancía que se compra y se vende en el mercado abierto, el ejemplo por excelencia, es el agua. Para las personas que consideran que el agua es un bien común, se propone que haya agua para todos los seres humanos $y$ para toda la naturaleza, tal y como las poblaciones indígenas no conciben que una persona o una familia no puedan tener acceso básico al aire, al agua y a todos aquellos recursos que les permita sobrevivir.

Sánchez Rubio (2009) plantea que los bienes comunes fueron perdiendo su condición comunitaria o colectiva $y$ experimentaron un proceso de privatización con fines comerciales. Agrega el autor, que es así como, se les fue quitando la dimensión solidaria, pública e inclusiva. Actualmente este proceso se acentúa, tal y como lo plantea Karl Polanyi, como "el proceso de mercantilización de todas las parcelas de la vida", dinámica que provoca consecuencias excluyentes.

El Foro Internacional sobre la Globalización propone tres tipos de bienes comunes:

1) Un primer tipo que contempla el agua, la tierra, el aire, los bosques, las reservas de peces, es decir, aquellos recursos biológicos de los cuales depende la vida de la humanidad.

2) Un segundo tipo que incluye la cultura y el conocimiento, que le llaman "creaciones colectivas de nuestra especie".

3) El tercer tipo son los bienes comunes sociales, los cuales señalan los participantes de este foro, son los que garantizan el acceso público a la salud, la educación y la seguridad social.

El presente artículo se concentrará en el primer tipo de bienes comunes, el de aquellos recursos de los que depende nuestra vida. Se comparte el supuesto del que parte Helfrich:

... que la capacidad de desarrollo de la sociedad, de toda sociedad, depende de manera decisiva de su aptitud para resolver el desafío de hacer justicia respecto a los criterios de equidad de acceso y uso de nuestra herencia común, de garantizar la participación activa en la gestión de los commons $y$ de velar por la sustentabilidad ecológica y social. El debate en torno a la responsabilidad por nuestros recursos colectivos, por lo tanto, es también 
un debate sobre cómo está constituida nuestra sociedad (2008: 326).

Pero, ¿qué son los bienes comunes (también denominados, ámbitos comunes, procomún, recursos comunes, recreaciones, cuidados, entornos y espacios locales)?

A continuación, se mostrarán diferentes definiciones, que por estricto sentido analítico se van a agrupar según tres grandes categorías ${ }^{2}$, una primera que alude a los bienes comunes como un recurso determinado; una segunda categoría que define los bienes comunes como una relación social entre el

2 Agradecemos a la Licda. Sindy Mora Solano, investigadora del Instituto de Investigaciones Sociales de la Universidad de Costa Rica, integrante del Programa Nuevas Formas de Acumulación, Distribución y Desigualdad, quien nos sugirió esta clasificación y fue avalada por el resto del grupo del programa. recurso y una comunidad específica y una tercera categoría que contempla la segunda pero va más allá, en tanto, definen los bienes comunes como recursos que generan propuestas políticas.

Los bienes comunes vistos como un recurso determinado (ver Tabla 1) y como una suerte de cosificación, los cuales no son propiedad de una persona sino que son compartidos por un grupo o una comunidad. Esta concepción como lo explica Flórez (2008), ve a los recursos en sí, como los bienes comunes que deben ser heredados, independientemente de quien es la figura que administra estos recursos.

La segunda categoría de bienes comunes, entendidos como una relación entre la comunidad y el recurso (ver Tabla 2), propone que estas relaciones conforman las redes de la vida que nos sustentan; son por lo tanto los bienes comunes, entornos naturales o culturales, una

\section{COMO UN RECURSO DETERMINADO}

\begin{tabular}{|c|c|c|c|c|}
\hline $\begin{array}{l}\text { Vercelli define los bienes } \\
\text { comunes como una } \\
\text { caracterización de } \\
\text { aquellos bienes que se } \\
\text { producen, se heredan o } \\
\text { se transmiten en una } \\
\text { comunidad. "Son bienes } \\
\text { que pertenecen y } \\
\text { responden al interés de } \\
\text { todos y cada uno de los } \\
\text { integrantes de una } \\
\text { comunidad". Él considera } \\
\text { que esta definición no } \\
\text { permite analizar el tipo } \\
\text { de relaciones sociales, } \\
\text { políticas o económicas } \\
\text { que se producen sobre } \\
\text { los bienes comunes; sin } \\
\text { embargo, considera el } \\
\text { autor, este término si } \\
\text { describe algunos rasgos } \\
\text { básicos que caracteriza } \\
\text { aquello que es "común". }\end{array}$ & $\begin{array}{l}\text { Richard Bocking define a } \\
\text { los ámbitos comunes } \\
\text { como esas cosas a las que } \\
\text { tenemos derecho por el } \\
\text { simple hecho de ser parte } \\
\text { de la familia humana, de } \\
\text { la comunidad humana. }\end{array}$ & $\begin{array}{c}\text { Margarita Flórez, por su } \\
\text { parte, hace referencia a } \\
\text { tres concepciones: la } \\
\text { originaria, la } \\
\text { administrativista y una } \\
\text { tercera derivada de la } \\
\text { segunda. La originaria } \\
\text { refiere a la relación que } \\
\text { tienen los pueblos } \\
\text { indígenas con el } \\
\text { territorio. La } \\
\text { administrativista le } \\
\text { concede el dominio de } \\
\text { los recursos al Estado, es } \\
\text { lo que se suele } \\
\text { denominar como bienes } \\
\text { de uso público o bienes } \\
\text { de la Nación. Y } \\
\text { finalmente la tercera } \\
\text { concepción, se deriva de } \\
\text { la administrativista, el } \\
\text { Estado opera como } \\
\text { administrador de los } \\
\text { bienes fiscales. }\end{array}$ & $\begin{array}{c}\text { Antonio Lafuente opta } \\
\text { por el término procomún } \\
\text { entendido como espacios } \\
\text { institucionales en los que } \\
\text { podemos practicar un } \\
\text { tipo particular de } \\
\text { libertad: libertad } \\
\text { respecto a las } \\
\text { restricciones que } \\
\text { aceptamos normalmente } \\
\text { como precondiciones } \\
\text { necesarias para el } \\
\text { funcionamiento de los } \\
\text { mercados ... su } \\
\text { característica } \\
\text { prominente, ... es que } \\
\text { ninguna persona } \\
\text { individual tiene un } \\
\text { control exclusivo sobre el } \\
\text { uso y la disposición de } \\
\text { cualquier recurso } \\
\text { particular ... los recursos } \\
\text { gobernados por } \\
\text { procomún pueden ser } \\
\text { usados por, o estar a } \\
\text { disposición de cualquiera } \\
\text { que forme parte de cierto } \\
\text { número de nersonas. }\end{array}$ & $\begin{array}{c}\text { Nayalli Loya trata de } \\
\text { definir bienes comunes } \\
\text { como "creaciones } \\
\text { naturales y de la sociedad } \\
\text { que heredamos de } \\
\text { manera conjunta y libre y } \\
\text { que mantenemos en } \\
\text { custodia de manera } \\
\text { conjunta para futuras } \\
\text { generaciones". }\end{array}$ \\
\hline
\end{tabular}




\section{COMO RELACIÓN SOCIAL}

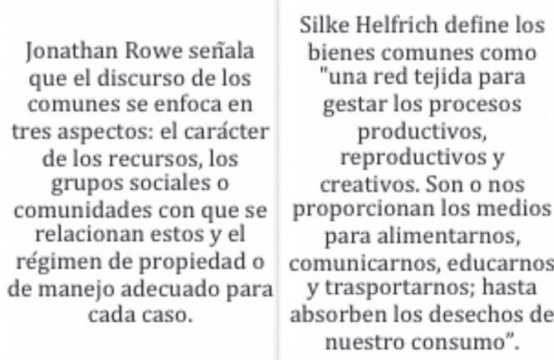
cada caso.

Silke Helfrich define los bienes comunes como "una red tejida para gestar los procesos productivos, reproductivos y creativos. Son o nos proporcionan los medios para alimentarnos, comunicarnos, educarnos absorben los desechos de nuestro consumo".

Elinor Ostrom refiere a la relación social entre la comunidad y su entorno natural y cultural. La importancia que las respectivas comunidades se sientan vinculadas al bien común, en tanto puedan hacer uso de su patrimonio e interesarse por la conservación y la reproducción del bien.

Andrés Barreda,
manifiesta la importancia
de no introducir un
enfoque cosificado sino
más bien "dimensionar
acerca de lo qué es lo
común, lo comunitario o
lo social y cómo la
propiedad privada
atomiza y rompe las
conexiones sociales".
Gustavo Esteva refuerza
la posición de Barreda al
considerar que common
no es un bien sino más
bien se trata de una
relación social y que un
common no existe sin un
sujeto social específico.

Para Stephen Gudeman los bienes comunes son el elemento material o conocimiento que comparte un pueblo. Cualquier elemento que contribuya al sostén material y social de un pueblo con identidad compartida, como la tierra, el almacenamiento básico de semillas, los rituales. "No son un incidente físico sino un evento social. Si se quitan, queda destruida una comunidad, $y$ la destrucción de un complejo de relaciones demuele a los commons".

Fuente: elaboración propia a partir de Barlow (2008: 3), Helfrich y Haas (2008: 315), Helfrich (2008: 21 y 47).

identidad común que sin comunidad no tendría razón de ser.

Los bienes comunes son entonces un “... ámbito que incluye a gente, personas y grupos diferentes que confluyen, convergen, concurren para poder realizar la gestión en común... El ámbito mismo es lo que todos tenemos en común" (Helfrich, 2008: 48). Son un conjunto de variables que interaccionan entre sí y conforma esta identidad común y por lo tanto, un concepto nuevo de ciudadanía y de comunidad.

Por último, la tercera categoría para comprender los bienes comunes, es entendiéndolos como una práctica política (ver Tabla 3) la cual explica como existe una forma de organización comunal que busca emanciparnos del propio sistema mercantilista y monopólico que se ha venido apropiando de nuestros recursos. Como nos dice Silke Helfrich, analizar estos temas siempre implica analizar las relaciones de poder que dominan cada contexto específico (Helfrich, 2008: 42).
Para David Bollier los bienes comunes pertenecen a la gente, son compartidos, de ahí lo de común, no pertenece al gobierno y por ello, sus intenciones son más amplias que las que ofrece el mercado, porque para este autor, cuando un bien pertenece al gobierno, el vínculo moral y legal con la ciudadanía empieza a diluirse. Y por ello, al hablar de bienes comunes se reafirman los derechos morales y legales de la población para "cosechar los beneficios de estos recursos $y$, de esta forma, mantenerlos" (2008: 37-38).

Todas las referencias señaladas sobre bienes comunes son complementarias y no excluyentes, aun cuando algunas apuntan a las características del recurso en sí, al tipo de régimen de propiedad que emboca los bienes comunes, otras apuntan a la diversidad territorial y espacial de los bienes comunes, diversidad de comunidades $y$ de mecanismos e instituciones de manejo de recursos colectivos, la característica local que tiene los bienes comunes. 
TABLA 3

DEFINICIÓN DE BIENES COMUNES COMO PROPUESTA POLÍTICA

\section{COMO PROPUESTA POLÍTICA}

\begin{tabular}{|c|c|c|c|c|}
\hline $\begin{array}{l}\text { Commons se entiende } \\
\text { como concepto que da } \\
\text { sentido y dirección a una } \\
\text { propuesta política y que } \\
\text { nos sitúa en tres temas } \\
\text { esenciales: } 1 \text { ) el acceso a } \\
\text { recursos y bienes que } \\
\text { conforman nuestro } \\
\text { patrimonio social, } \\
\text { natural y cultural; } 2 \text { ) el } \\
\text { proceso de producción y } \\
\text { reproducción social tanto } \\
\text { de bienes como del bien } \\
\text { común y } 3 \text { ) la } \\
\text { distribución equitativa } \\
\text { en la repartición de los } \\
\text { beneficios que emergen } \\
\text { de nuestro acervo } \\
\text { común. }\end{array}$ & $\begin{array}{l}\text { David Bollier expresa que } \\
\text { "un "recurso de uso } \\
\text { común" es un bien } \\
\text { económico compartido, } \\
\text { independiente de } \\
\text { cualquier sistema de } \\
\text { derechos legales de } \\
\text { propiedad... un recurso } \\
\text { poseído en conjunto } \\
\text { mediante una serie de } \\
\text { derechos legales". } \\
\text { Es presionar al gobierno } \\
\text { para que en sus objetivos } \\
\text { priven intereses más } \\
\text { amplios, por encima de } \\
\text { los del mercado. }\end{array}$ & $\begin{array}{l}\text { Jean Pierre Leroy se } \\
\text { refiere a esta perspectiva } \\
\text { de visualizar los } \\
\text { commons como una } \\
\text { relación social y como tal, } \\
\text { como una visión política } \\
\text { y expresa de que hay } \\
\text { comunes "cuando hay } \\
\text { lucha, acción, resistencia } \\
\text { y propuesta". Propuesta } \\
\text { para contribuir a la } \\
\text { protección, recuperación } \\
\text { o reproducción de } \\
\text { nuestro patrimonio } \\
\text { natural, social y cultural, } \\
\text { claro está, vinculada a } \\
\text { diversas comunidades } \\
\text { que subsisten y tienen } \\
\text { muy presentes el lazo } \\
\text { que los une a sus bienes } \\
\text { comunes. }\end{array}$ & $\begin{array}{c}\text { Ulrich Brand se refiere a } \\
\text { los bienes comunes como } \\
\text { una crítica a los procesos } \\
\text { de utilización y a las } \\
\text { dinámicas de propiedad } \\
\text { capitalistas; sin embargo, } \\
\text { plantea el autor, lo } \\
\text { anterior no significa que } \\
\text { las prácticas y } \\
\text { propuestas de los } \\
\text { comunes sean críticas y } \\
\text { emancipadoras per se. }\end{array}$ & $\begin{array}{c}\text { Para Sánchez Rubio, } \\
\text { conlleva cierta } \\
\text { connotación influida por } \\
\text { una cultura mercantilista. } \\
\text { Plantea que nada básico } \\
\text { para la supervivencia } \\
\text { humana puede ser objeto } \\
\text { de monopolio, } \\
\text { mercantilización y de } \\
\text { privatización, bajo la } \\
\text { lógica del capital. } \\
\text { Delimita la titularidad y } \\
\text { la gestión local de los } \\
\text { bienes comunes a partir } \\
\text { de los movimientos } \\
\text { sociales y vincula el } \\
\text { concepto de bienes } \\
\text { comunes con el concepto } \\
\text { sociohistórico de } \\
\text { derechos humanos } \\
\text { basado en las } \\
\text { experiencias y prácticas } \\
\text { concretas de los } \\
\text { movimientos sociales }\end{array}$ \\
\hline
\end{tabular}

Fuente: elaboración propia a partir de Helfrich (2008: 37-38, 42) y Sánchez (2009).

Se optó por una definición de bienes comunes, tal y como lo plantean Helfrich y Haas, como un concepto político que contempla una relación social entre los recursos, los bienes y su vínculo con un grupo de personas de una comunidad específica. Estos bienes son básicos para la sobrevivencia humana y por lo tanto, la comunidad los ve como suyos. Es así como tienden a cuidarlos con mucho respeto y muy responsablemente para sí y sus futuras generaciones. Este vínculo especial entre bienes $y$ personas de una comunidad permite la construcción de un tejido social fundamental para la defensa de la equidad, el acceso colectivo, la responsabilidad compartida y el disfrute de los beneficios del proceso de preservación del ecosistema.

Es importante en estos tiempos de globalización de pobreza, desigualdades sociales $y$ amenazas permanentes al medio ambiente, permitirse soñar $y$ aunque ciertos planteamientos suenen a utopías, alimentar estas utopías, podría lograr que quizás algún día se concreten. En este sentido, Vandana Shiva nos habla de "Democracia de la Tierra" y lo define como "un sistema donde las personas y la naturaleza tienen prioridad por encima del comercio y el lucro, un sistema que surge del deseo de sustentar la vida para las generaciones futuras" (Barlow, 2008: 29-30).

La Democracia de la Tierra refiere a un conjunto de prácticas que sustentan la vida y preservan el ecosistema. La rendición de cuentas es un componente fundamental de la Democracia de la Tierra, tal y como se declaró en el Foro Internacional sobre la Globalización. Su punto de partida es que si las decisiones son tomadas por la población que va a enfrentar las consecuencias, es más probable que prioricen "la salud de su suelo, sus bosques, su aire y su agua, porque lo que está en juego es su propio bienestar y el de sus hijos". Plantea esta autora, que para el buen éxito de la Democracia de la Tierra se requiere que el gobierno respectivo deposite su 
confianza en estas poblaciones que toman las decisiones y le harán frente a las consecuencias de las decisiones tomadas, esto significa, poner límites a los derechos de terratenientes que no trabajan su tierra y a las empresas extranjeras, asegurando que quienes provoquen daños a las demás personas, asuman su responsabilidad civil. Por las características de esta Democracia de la Tierra, señala Shiva, que donde mejor se aplica es en las comunidades locales con mucha transparencia.

Esta propuesta es muy cercana a la de los bienes comunes, en sí es el mismo planteamiento, solo que Vandana Shiva la denominó como Democracia de la Tierra. Nosotros soñamos con ella y este artículo pretende sensibilizar al respecto, solo como un primer paso.

A continuación se hará referencia a algunos elementos que son importantes de señalar a cerca del debate de los bienes comunes.

\section{RELEVANCIA DEL DEBATE DE BIENES COMUNES}

Lo que interesa con este artículo es aportar a la comprensión de los conflictos socioambientales (como por ejemplo, las luchas por el agua en Sardinal, la minería a cielo abierto en Crucitas, la piña y su contaminación para los y las trabajadoras, entre otras luchas) que se han venido presentando en Costa Rica.

¿QUÉ HAY DETRÁS DE ESTOS CONFLICTOS SOCIOAMBIENTALES? ¿ES ALGO PARTICULAR DE ESTE PAÍS U OBEDECE A UNA DINÁMICA DEL MODELO ECONÓMICO NEOLIBERAL?

Con la consagración de la globalización económica y el fundamentalismo de mercado como único modelo de desarrollo para todo el mundo, tal y como lo plantearon en el Foro Internacional sobre la Globalización en 2006, México:

... la integridad y salud de los ámbitos comunes... se fracturó... Las empresas transnacionales consiguieron así acceso quizá por primera vez a los recursos genéticos, minerales, la madera $y$ los recursos hídricos... Algunos se refieren a este proceso como el segundo "cercamiento de los ámbitos comunes" (Barlow, 2008: 4).

Segundo cercamiento, porque el primero es el anteriormente mencionado planteamiento de Hardin y su Tragedia de los comunes. A pesar de los años transcurridos, este mismo señalamiento se sigue utilizando hasta el día de hoy, sin considerar lo que muchos investigadores (Barnes, 2006; Helfrich, 2008; Barlow, 2008) indican que Hardin hizo completamente caso omiso de la capacidad y el potencial que han demostrado los sistemas de manejo basados en la propiedad comunitaria "de proporcionar una custodia sólida y sostenible de los ámbitos comunes biológicos y los ecosistemas, cuando estas estructuras de manejo comunitario existen y son alentadas" (Barlow, 2008: 4). Claro está, que no se está defendiendo una concepción de bienes comunes abiertos y de libre acceso para cualquier persona, es necesaria la implementación de controles a los recursos públicos, empero, la tesis de Hardin ha sido utilizada para destruir los sistemas comunitarios existentes y fomentar la privatización de estos bienes.

En la lógica del modelo económico neoliberal, los valores de inclusión, propiedad colectiva y capital comunitario, fueron sustituidos por valores de exclusión, posesión, monopolio y lucro personal o empresarial elevados por el sector privado. Muchas áreas que se consideraban fuera del mercado pasaron a ser de gran interés para este sector privado, provocando una competencia despiadada:

... de un lado, por el control y las ganancias derivadas de la tierra, los recursos genéticos, el agua, los minerales, y los bosques como objetos de lucro, arrebatándoselos a los ámbitos comunes y convirtiéndolos en mercancías; $y$ de otra parte, por el uso del aire, los océanos y el agua dulce como vertederos de desechos (transfiriendo así a la esfera pública los problemas creados por el cercamiento de los ámbitos comunes, de manera tal que todos tengamos que sufrirlos o hacernos cargo de limpiarlos) (Barlow, 2008: 5). 
Se coincide con lo señalado por Sánchez Rubio (2009), que el capitalismo requiere que todos los bienes funcionen como mercancías y que los ingresos procedan de relaciones mercantiles; así, se transforman los medios de producción y de vida en capital y la fuerza de trabajo en mercancía. Agrega este autor, que el capital no admite coexistir con otras concreciones sociohistóricas (otros modos culturales de producción) $\mathrm{u}$ otras formas de entender las relaciones sociales, otros sistemas de cuidar, usar y disfrutar los espacios naturales o inclusive, distintos tipos de conocimiento.

Los defensores de esta lógica de mercado atribuyen un valor monetario a todo (tierra, cosechas, agua, arte, conocimiento), todo es visto como mercancía y se ocupan de maximizar el valor de intercambio económico de esos recursos, según lo determina el precio. Los bienes comunes son vistos como insumos brutos para generar utilidades empresariales. Muy astutamente, tienden a no considerar los costos desplazados al medio ambiente, a los y las trabajadoras y a la ciudadanía, en general, estos son conocidos como "externalidades económicas”. En otras palabras:

Un mercado puede ser muy productivo $y$ eficiente $y$, al mismo tiempo, no reconocer que está destruyendo los recursos comunes: contaminación arrojada al medio ambiente, niños usados como mano de obra, fábricas que plantean graves riesgos para la seguridad (Bollier, 2008: 32).

Estos daños los están asumiendo las instituciones gubernamentales. Asimismo, tal y como lo plantea Bollier, en el neoliberalismo, los derechos de propiedad significan la manera más eficiente para producir riqueza y por tanto "progreso".

Muchos de los conflictos que acontecen en nuestras sociedades, se generan por la erosión de los recursos, por la concentración de los derechos de uso y por la disposición sobre estos recursos, el acceso a ellos. Estos procesos de concentración tienen efectos inmediatos sobre los derechos de uso de toda la población y sobre la vitalidad y la diversidad de nuestra herencia natural y cultural (Helfrich y Haas, 2008: 312).

\section{¿QUÉ NOS APORTA EL DEBATE DE BIENES COMUNES?}

Los bienes comunes han sido una realidad en todo momento, pero se releva su importancia al surgir los problemas de acceso a ellos, al perderse la calidad y la vitalidad de los recursos y al erosionarse la conciencia de tantas relaciones sociales, que se tejen a partir del proceso de producción y reproducción de los bienes comunes. Toman importancia al ser vistos como mercancías, como propiedad privada para poder comprar $y$ vender en el mercado. Es justamente, la pretensión de privatizar los bienes comunes lo que impulsa el debate sobre estos (denominado también como comodificación). El proceso en que los defensores del mercado (tanto del sector privado como los de los gobiernos) desean e impulsan la privatización de recursos que son o por lo menos deberían ser, propiedad colectiva de la gente, es lo que se denomina como el "cercamiento de los bienes comunes".

Siguiendo con la lógica del mercado, dice Víctor Galaz (2003), que crear mercado a partir de recursos ambientales brinda incentivos para aumentar la eficiencia económica y medioambiental, lo cual se ha demostrado que es falaz, en tanto que el estado del medio ambiente se ha agravado a partir de estas políticas abiertamente liberales. Por el contrario, propone Bollier (2001: 4) que el cercamiento de los bienes comunes favorece la explotación a corto plazo sobre la administración a largo plazo, provocando contaminación de la tierra, el aire y el agua, así como, riesgos para la salud y la seguridad de la humanidad, incluidas las generaciones futuras. Como ejemplos de lo planteado, señala Bollier, el abuso de tierras públicas por parte de empresas madereras, empresas mineras $y$ agroindustriales.

Se supone que el papel del gobierno es ser guardián de los recursos de la ciudadanía; sin embargo, en las sociedades de mercado, con mucha frecuencia ocurre que las y los políticos $y$ las instituciones gubernamentales no cumplen con su tarea, menciona Bollier que "hay quienes sostienen que es una falla sistémica del neoliberalismo" (2008: 32). Con el crecimiento 
del sector del mercado en décadas recientes, los gobiernos, incluidas las instituciones estatales, lo que han venido haciendo es ceder a las presiones que los sectores del mercado realizan para cercar a los bienes comunes y así, protegen los intereses económicos de la iniciativa privada y no los de la ciudadanía en general. Recursos que durante siglos se percibían como bienes a los cuales toda la población tenía derecho, fueron convertidos en mercancías. Y como se mencionó anteriormente, los daños ecológicos, sociales y culturales provocados por el cercamiento de los bienes comunes por parte de la empresa privada son desplazados al gobierno.

Acá es fundamental hacer la distinción, que hablar de bienes comunes no es sinónimo de bienes públicos. No es lo mismo uno y otro, los bienes públicos son los administrados bajo la jurisdicción del Estado, no necesariamente son bienes comunes, ya que como hemos señalado, el Estado per se no da garantía de defender el acceso, mantenimiento y distribución de los recursos vitales para sobrevivir, para cada una de las personas en el presente y para las futuras generaciones.

En esta misma dirección, Sánchez Rubio indica que:

Pese a que en un principio la institución del Estado ha sido un instrumento útil de protección frente al control privado al tener la responsabilidad de velar por el bienestar de la población en su conjunto, al final, en el contexto actual está pasando a ser un aliado más del capital. ... pese a representar internamente el ámbito público, en su proceso de expansión externa, ha sido también un arma de exclusión frente a otras culturas y colectividades (2009).

Sánchez Rubio nos recuerda que muchos de los recursos naturales que los estados consideran "públicos", fueron arrebatados violentamente de las manos de muchas culturas, pueblos y colectivos, como por ejemplo, los pueblos indígenas.

Agrega este autor que el neoliberalismo está destruyendo esta responsabilidad que ha tenido el Estado y actualmente, son muchos los Estados que actúan como agentes activos del ya mencionado proceso de privatización. Considera que el control estatal puede ser un factor clave en el mantenimiento o agudización de la inequidad $y$ la injusticia.

Es así como, al posicionar los bienes comunes, se contribuye a reinstalar en el centro del escenario una extensa variedad de fenómenos sociales y ecológicos que la lógica de mercado considera "externalidades económicas", como se ha señalado anteriormente. Tematizar los bienes comunes significa establecer un diálogo más amplio sobre los tipos de riqueza $y$ de valor, significa plantear que no toda riqueza se puede expresar mediante un precio de mercado y que se hace necesario reconocer y resguardar otros tipos de valores como lo son el ecológico, el social, el democrático y el moral. Bollier plantea:

Hablar de bienes comunes nos ayuda a identificar una amplia clase de recursos en cuyo control y manejo, la ciudadanía en general o comunidades específicas tienen intereses políticos y morales. Una gran cantidad de estos recursos se está convirtiendo en propiedad privada para poderlos comprar $y$ vender en el mercado (2008: 31).

Es importante resaltar que los bienes comunes están siendo resignificados como recursos que deben ser disfrutados universalmente por toda la humanidad y por ello, se plantean como recursos por y para comunidades específicas y no se está hablando de comunes globales (Sánchez, 2009).

El propósito de hacernos eco del debate sobre bienes comunes es restablecer un mayor control democrático, empoderar a las comunidades en el cuidado, acceso equitativo, sostenibilidad y distribución de los mismos frente a la propiedad privada. El grito por los bienes comunes es un grito por un nuevo espíritu de comunidad, por anteponer el interés del bien común al mercado. El discurso de los bienes comunes permite visualizar las características estructurales de la época en que se vive.

Lo anteriormente planteado por Bollier se complementa muy satisfactoriamente con lo 
expuesto por Fikret Berkes (1989: 11-13), quien señala que los bienes comunes cumplen cinco funciones en las comunidades: 1) son medios de vida en tanto garanticen el acceso equitativo de las personas en la comunidad; 2) ayudan en la resolución de conflictos sobre el uso y aprovechamiento del bien, ya que colabora en el establecimiento de reglas y en la aprobación de las mismas; 3) facilita la creación de estas reglas, ya que aquellos que conviven tienen una cultura en común; 4) permite la conservación del recurso hasta llevarlo a la autosuficiencia necesaria para la supervivencia, tanto del recurso como de la comunidad y por último, 5) todo lo expuesto se ve reflejado en la herencia del recurso de generación en generación evitando su agotamiento.

Desde otra perspectiva pero complementario con lo planteado por Berkes, Bollier (citado por Barlow, 2008: 5) expone que es importante preocuparse por la creciente explotación de nuestros bienes comunes por parte del mercado, porque este cercamiento absorbe innecesariamente miles de millones de dólares por año de las arcas públicas; dinero que podría utilizarse para invertir y proteger los bienes comunes. Asimismo, agrega, el cercamiento de los bienes comunes fomenta la concentración del mercado y el predominio de las grandes empresas, ya que estas controlan el mercado y tienen la suficiente influencia política como para obtener bienes comunes en condiciones favorables. Por otra parte, el cercamiento amenaza al medio ambiente, al favorecer el lucro a corto plazo, en vez del cuidado a largo plazo. Además, impone nuevos límites a los derechos ciudadanos y la rendición pública de cuentas, esto porque la toma de decisiones en manos privadas sustituye los procedimientos abiertos de la democracia política. Como se mencionó anteriormente, el cercamiento de bienes comunes impone los valores del mercado en bienes que deberían estar al margen de las fuerzas de la mercantilización. Algunas comunidades podrían decidir la venta de recursos en el mercado, pero solo si se puede hacer de manera sustentable $y$ sin causar daño a la integridad de los bienes comunes.
Señala Bollier (2001: 85) que una cultura que respete a los bienes comunes se caracterizaría por ser una comunidad democrática, en cuyo seno, los miembros toman decisiones y aumentan su conocimiento de gobernanza, brindando legitimidad al régimen. Establecen límites claros al mercado e intentan satisfacer las necesidades humanas fuera de la actividad del mercado. Crear espacios públicos que permitan formas de interactuar, en los que una comunidad haga comunes sus preocupaciones $y$ actividades, de manera que se pueda romper con el individualismo competitivo e incentivar la "economía del regalo". Así como Bollier (2008) plantea al software libre como un intento cooperativo que puede funcionar al difundir conocimientos y obras creativas.

En síntesis, plantea Bollier (2008: 4), los bienes comunes responden a un nuevo paradigma "para la creación de valor y la organización de una comunidad de intereses compartidos... por el cual nuevos tipos de grupos autoorganizados pueden reunirse $y$ ejercer nuevas formas de ciudadanía".

Ulrich Brand (2008: 306) indica que con el discurso de los bienes comunes, los términos "común" y "público" se fortalecen en contra de lo económico capitalista-privado. Él considera que el abrir espacios para el intercambio, para los procesos de aprendizaje $y$ para experiencias alternativas que minen la competencia $y$ la apropiación privada de la riqueza producida por la sociedad, ya son bienes comunes en sí mismos. Agrega que los bienes comunes refieren a una estrategia en contra de las tendencias dominantes de la privatización, de la desregulación, de la comodificación y la valorización monetaria de los procesos sociales y naturales.

\section{CARACTERÍSTICAS DE LOS BIENES COMUNES ¿CÓMO ORGANIZARSE PARA SOCIABILIZAR FUERA DEL MERCADO?}

El debate en la literatura en las últimas décadas favorece la postura de los bienes comunes como la relación de una comunidad y un recurso común, el estudio de esta relación y sus características toma importancia, en tanto permite revisar casos exitosos de uso del recurso por fuera de las relaciones del mercado mundial 
y como las comunidades se mantienen con el pasar de los años sin permitir la apropiación del recurso.

De acuerdo con esta concepción de los bienes comunes, en la relación entre la comunidad y el recurso común, se presentan características particulares y propias en cada caso, por lo que se ha realizado un esfuerzo bastante grande para definir qué se debe tomar en cuenta a la hora de analizar un caso de este tipo. La literatura, a través del estudio de casos, ha comenzado a otorgar una serie de características básicas y necesarias para hablar de bienes comunes, estas deben buscar siempre la supervivencia del bien para futuras generaciones.

Los bienes comunes coexisten en un flujo de variables dentro del cual se dan distintos tipos de relaciones entre los bienes y los ciudadanos que conviven con el recurso, la más común es la apropiación, esta se da mediante un proceso de sustracción, como entrada a procesos de producción ${ }^{3}$; debido a esto los apropiadores son también proveedores de estos recursos a otros (Ostrom, 2000: 68), es así como, la capacidad de sustracción es inherente a todo bien común. Una segunda característica es la exclusión que existe en el recurso, debe evitarse la explotación del recurso, por lo que no se permite su uso indiscriminado, por ejemplo, en las compañías, se excluye el uso del recurso con fines mercantiles (Berkes, 1989: 7). Estas dos características inherentes al propio recurso son importantes para entender la clasificación propuesta en la literatura, en los últimos años.

Los bienes comunes de acuerdo a la literatura revisada, pueden clasificarse de acuerdo a su carácter o por sus características (ver Tabla 4). Esta clasificación es un intento de recopilación de lo expuesto en el debate de los bienes comunes en los últimos años, de manera que facilite la compresión de este tema.

Los bienes comunes pueden clasificarse de acuerdo con su carácter o su gestión; por su carácter se entienden tres categorías bastante

3 El proceso de producción al que refieren autores como Ostrom (2000) y Bollier (2001), comienza con el recurso común que pasa a ser materia prima para luego transformarse en una mercancía que genera una ganancia en el mercado. amplias: 1) regalos de la naturaleza por ejemplo, ríos, montañas y vida silvestre; 2 ) creaciones materiales así como, bibliotecas, parques, etc. y 3 ) creaciones intangibles como investigaciones científicas o avances tecnológicos, un claro ejemplo es el software libre (Bollier, 2008a: 31). Esta clasificación también permite dividirlos en dos clases de bienes comunes: materiales e intelectuales; siendo los primeros de los que se ocupa este estudio y que a su vez se caracterizan por ser limitados, finitos, consumibles y escasos (Vercelli, 2006: 54), por lo tanto, esta clasificación ayuda a separar las creaciones humanas de los bienes naturales.

De acuerdo a su gestión, define más el tipo de manejo y de protección sobre el bien común, si es estatal, de uso libre o si es solo de los usuarios. Como lo explica Berkes, lo primero que se debe hacer es lanzar la pregunta ¿quién es el dueño del recurso?; si bien es cierto nadie es dueño de los recursos naturales, pero para la protección del bien común, la comunidad, estado o grupo que mantiene un vínculo con el bien, limita el acceso al uso del recurso $y$ establece una serie de normas o reglas. En relación con las reglas establecidas, la extracción o utilización del recurso va a repercutir en la capacidad de su uso por parte de los demás miembros de la comunidad (1989) y a esto es lo que se le denomina capacidad de sustracción.

En este sentido, de acuerdo con la gestión ${ }^{4}$ sobre el recurso se puede listar la propiedad estatal ${ }^{5}$, tales como tierras públicas, la investigación y el desarrollo del gobierno, los recursos de información pública; la naturaleza tal como existe fuera del mercado, compuesto por este tipo de sistemas planetarios como la atmósfera, el agua, los ecosistemas locales, las ondas y las estructuras genéticas de la vida;

4 Por gestión Bollier (2008) y Berkes (1989) hacen referencia a las reglas para el uso de bien común. Estas reglas implican temas como la vigilancia, protección y sanción sobre el uso del bien común, así como, la entrada de usuarios.

5 Es importante dejar en claro que si se habla de propiedad estatal, se está hablando de bienes públicos, que se diferencian de los comunes en que no existe la capacidad de exclusión, su uso no se encuentra regulado y todos tienen libre acceso a él, así como, tampoco existe capacidad de sustracción. 


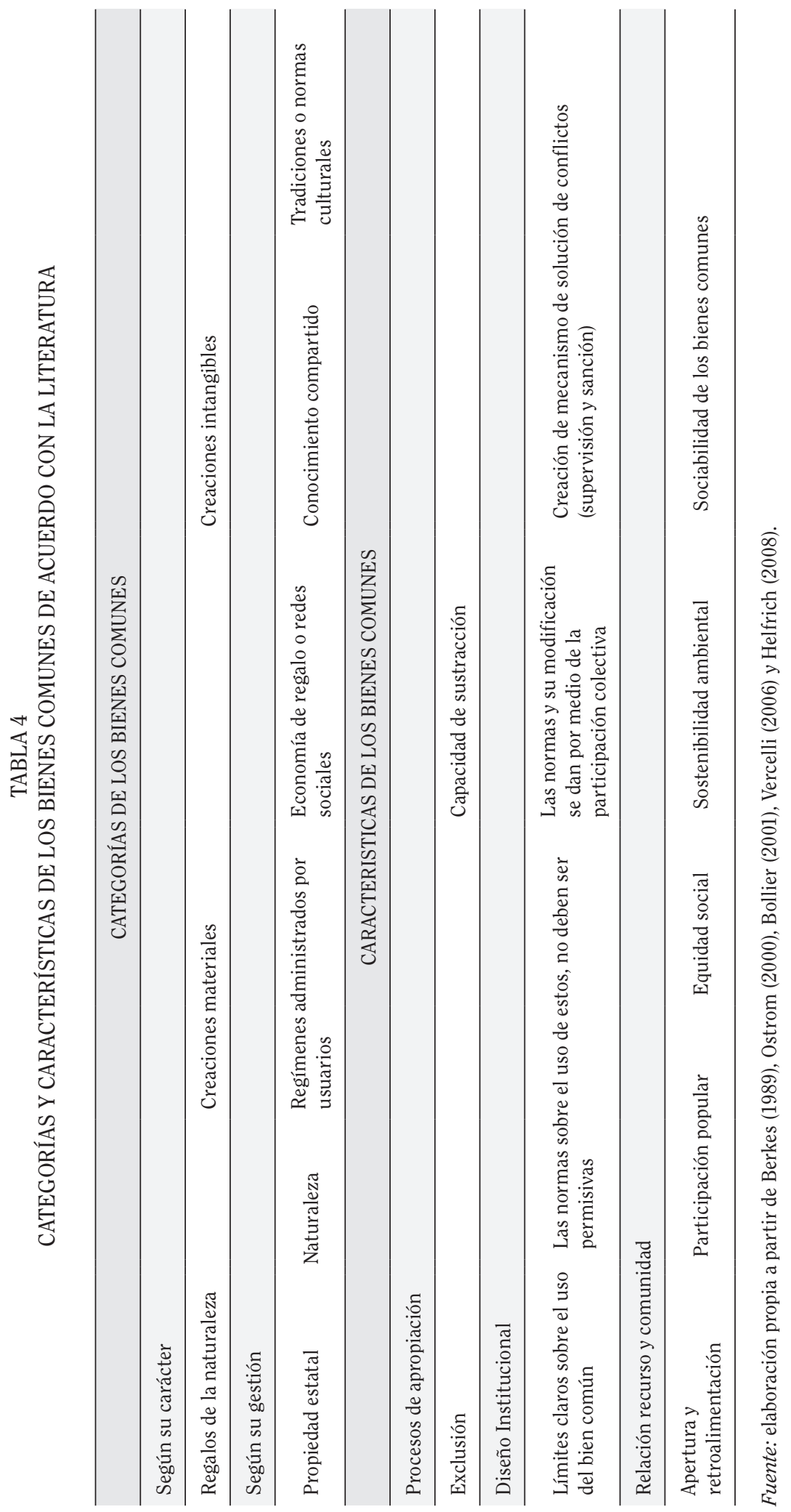


regímenes administrados por el usuario para la conservación de tierras, los huertos comunitarios, desarrollo de software, pesca, suministros de agua y decenas de otros recursos. Economías de regalo o redes sociales basadas en el intercambio de regalos, que existen en el mundo académico, las comunidades de internet y las comunidades locales; compartir, heredar conocimiento como la investigación científica, el conocimiento histórico y la sabiduría popular, tradiciones $y$ normas culturales, que sirven como un conjunto de presunciones morales comunes $y$ las expectativas para la gestión de la vida cotidiana (Bollier, 2001: 13).

De esta manera, los bienes comunes deben estar adscritos a alguna institución, entendida esta como el conjunto de reglas que permite determinar quién tiene el derecho a tomar decisiones respecto a la utilización del recurso y a como este debe utilizarse (Bollier, 2001; Ostrom, 2000). Estas instituciones deben responder a ciertos problemas sobre los bienes comunes, los cuales están relacionados con la provisión, el compromiso de la comunidad y la supervisión de las normas. Estos tres puntos generan resultados beneficiosos para la comunidad, como lo son: crear el suficiente compromiso de parte de los miembros de la comunidad para respetar las normas sobre el aprovechamiento del bien común, sustraer de acuerdo con la capacidad del sistema en el cual se encuentra el bien común y permitir a los demás miembros utilizar el recurso; de manera que el gasto en supervisión sea mínimo.

En este sentido, existe una serie de principios necesarios para la consolidación del bien común: primero, los límites sobre el uso del bien común deben ser lo suficientemente claros y conocidos por los miembros de la comunidad, deben estar bien definidos y no solo ser del conocimiento de esta, sino también deben participar en el proceso de aprobación. Segundo, las normas de apropiación (uso) del recurso deben generar condiciones locales permisivas sobre el tiempo y las estrategias de apropiación de la comunidad hacia el recurso. Tercero, cualquier decisión sobre las normas y la modificación de las mismas deben ser de participación colectiva. Por último, la creación de un mecanismo de solución de conflictos que permita crear una situación de supervisión y de sanción para aquel que no cumpla con las normas (Ostrom, 2000: 82-86).

Como los bienes comunes "forman parte de un emergente cultural e identitario común" (Vercelli, 2006: 55), estos bienes nacen en comunidad y su objetivo es heredarlos a generaciones futuras, tal y como han sido heredados a la generación que actualmente los utiliza, transmitidos en situación de comunidad. El problema resulta que los bienes de carácter material y que son regalos de la naturaleza son finitos, si son explotados o sobre utilizados no podrán ser heredados, debido a que el recurso llegaría a su fin $y$ el bien común (que pertenece a todos $y$ a todas) dejaría de existir, por esta razón es que los estudios sobre bienes comunes tratan de vislumbrar cuales características son necesarias para mantener el equilibrio entre el uso del bien $y$ la supervivencia de este.

De acuerdo a Berkes (1989) los bienes comunes deben cumplir con las siguientes características:

1. Los recursos naturales deben ser propiedad común de toda la población.

2. El acceso debe ser abierto a los ciudadanos.

3. El acceso y uso debe ser libre de regalías o de rentas.

4. Cualquier límite estipulado sobre el acceso y uso del bien común está permitido solo cuando todos los usuarios brindan su aprobación.

5. Los bienes comunes son derecho de todo usuario, debido a las otras características $y$ nadie puede ser excluido arbitrariamente, pero sí puede ser excluido si no cumple con las normas o reglas sobre el bien común.

Algunos autores fundamentan estas características en ciertos objetivos a los que aspiran los bienes comunes, el bien común debe ser sustentable a perpetuidad, de manera que pueda transmitirse por generaciones ${ }^{6}$; los

$6 \quad$ Es claro el ejemplo que brinda Berkes (1989) de bienes comunes de larga duración, autorganizados 
bienes comunes no deben otorgar una carga indebida sobre alguno de sus usuarios ya que el manejo del sistema debe ser colectivo, por lo tanto, todos deben destinar los mismos recursos a la protección como al uso del bien; la administración o reglas de acceso y uso del bien común no debe ser opresiva, sino debe estar destinada a la supervivencia del propio recurso $y$ por último, las ganancias que se puedan obtener por el uso del recurso (en caso de que pueda existir ganancias económicas) debe distribuirse equitativamente entre la comunidad que mantiene la relación con el bien común.

La literatura más reciente parece darle mayor importancia a la relación entre comunidad $y$ recurso, esta relación es lo que se denomina bienes comunes. Entre sus mayores defensores se encuentra Barlow (2008), Bollier (2001), Helfrich (2008), Vercelli (2001, 2006); todos parecen afirmar que para la permanencia de los bienes comunes es necesario que esta relación sea abierta a los miembros de la comunidad y que a través de estos se den procesos de retroalimentación para la propia relación, con el fin de lograr su perpetuidad y por ende, la perpetuidad de la comunidad que sobrevive a través de la relación con el bien común.

En este sentido es importante que exista un diálogo constante $y$ abierto sobre las normas que se estipularon para el bien común, este diálogo estará determinado si las decisiones son compartidas por la comunidad en un flujo de "abajo hacia arriba" (Bollier, 2001: 24), de manera que exista una participación popular en su formulación.

Esta participación popular refiere a la diversidad dentro de la comunidad que mantiene una cercanía con el bien común, a pesar que la homogeneidad puede proporcionar ventajas en la gestión del recurso y a pequeña escala, en zonas rurales facilita $y$ fortalece el bien, es necesario entender que los bienes comunes se alimentan de la heterogeneidad de sus miem-

$y$ autogobernados con dos distintos casos en el monte Hirano, en Japón y en los Alpes Suizos; donde los campesinos se han organizado sobre el uso de la tierra compartida a través de siglos, ya que su supervivencia depende de esta corriente comunalista. bros y esto se da a través de la participación popular.

Si lo bienes comunes existen a través de la participación popular es debido a que buscan la equidad social, por lo tanto, el sistema de normas del bien común debe ser dirigido por razones sociales y prácticas, los bienes comunes no deben alimentar sistemas desiguales o privados (Bollier, 2001: 25); aun así, el sistema tampoco busca un igualitarismo estricto, debido a que cada individuo tiene un interés común distinto para compartir.

Por último, se argumenta que los bienes comunes (de carácter material que son regalos de la naturaleza) deben generar sostenibilidad ambiental, esto debido a la duración a través de los siglos que han tenido los bienes comunes sin perjudicar el ambiente, de manera que produzca una sociabilidad distinta de los seres humanos por fuera del mercado y del control estatal; es de esta manera, que los bienes comunes responden a la necesidad de proteger el medio ambiente.

Las características de los bienes comunes se pueden dividir en tres categorías: 1) las de los procesos de apropiación del bien, aceptada por toda la literatura en general; 2) las del diseño institucional de los bienes comunes, que refieren a la creación de normas en la comunidad de usuarios y 3) las que deben cumplir los bienes comunes para poder ser considerados como tales; ya que deben responder a una serie de ideales, que refieren a los objetivos que los bienes comunes tratan de responder, así como, la manera de mantener los recursos naturales fuera del mercado y evitar la mercantilización de los mismos.

Aún así, cada caso en el que exista una relación de bienes comunes, es distinto entre sí y estas características son las más aceptadas en la literatura; sin embargo, pueden agregarse o eliminarse categorías; estas fueron escogidas ya que responden a casos exitosos donde los bienes comunes han logrado mantenerse a lo largo de períodos amplios de tiempo y resistirse al mercado, supliendo a comunidades de condiciones básicas para su supervivencia.

Es importante recordar que la característica más importante de este tipo de bienes 
es que nacen en comunidad como una forma de alejarse de las relaciones del mercado, para crear un nuevo tipo de ciudadanía mucho más cercana con el entorno que la rodea (Vercelli, 2006).

\section{REFLEXIONES FINALES}

Interesa resaltar en este artículo que cuando se habla de bienes comunes, se hace referencia a estrategias en contra de la tendencia dominante neoliberal que implica la privatización, la desregulación, la comodificación y la valorización monetaria-mercantilista de los procesos sociales $y$ naturales, de la globalización económica. Como dice Silke Helfrich, estas estrategias de bienes comunes con una base social, no tienen porque desembocar en "una tragedia" como planteaba Hardin.

Es contra la lógica del aprovechamiento, la privatización y la explotación de la naturaleza para enriquecimiento de unas pocas personas que surge la propuesta de los bienes comunes. De lo que se trata es de aprender y seguir las enseñanzas $y$ conocimientos de nuestras $y$ nuestros maestros indígenas y campesinos, lo que implica la convivencia horizontal e inclusiva con la naturaleza, que responde a las necesidades de las comunidades, a un patrimonio común.

Se trata de proponer un conjunto de supuestos básicos, valores y modelos de comercio, intercambio, desarrollo y producción contrapuestos a la doctrina neoliberal y de globalización económica. Como propone Barlow:

Hay que dejar atrás este sistema y pasar a otro fundado en los conceptos de cooperación, sustentabilidad, equidad, control democrático y subsidiaridad (si algo se puede cultivar, producir o administrar a nivel local, es precisamente eso lo que se debe privilegiar frente a la opción de una solución regional, nacional o internacional). En este nuevo modelo, el sector privado quedaría sujeto al escrutinio público y a normas altas de calidad (2008: 29).

Hoy en día lo que se necesita es más propiedad común e instituciones que tengan como principal objetivo gestionar y proteger las mismas y con ello, los recursos naturales. Estas instituciones por razones obvias no pueden ser las empresas privadas y tampoco el gobierno, porque este es y pareciera que seguirá siendo, capitalista, neoliberal, patriarcal, racista e imperial. Como muy bien lo expresa Helfrich, la función principal del Estado no es la de ser árbitro, sino la de asegurar el orden de propiedad y la estructura social burguesa (2008: 309). De ahí la necesidad del surgimiento de nuevas estrategias que vayan más allá de las iniciativas del Estado social y la política del mercado laboral y la mercantilización. Un ejemplo del alejamiento de su función principal por parte del Estado neoliberal, son las zonas marítimo terrestres, en Costa Rica, en donde el Estado ofrece recursos naturales, específicamente el acceso a una playa o una linda vista, a empresas privadas para que estas lucren a través de los recursos ofrecidos, sin considerar las necesidades $y$ derechos de las comunidades circunvecinas.

Los bienes comunes es una práctica concreta que busca la paz y el bienestar para una convivencia solidaria, justa, libre y democrática. Podría sonar utópico pero ¿qué se pierde si se intenta? se podría ganar mucho, defendiendo, protegiendo $y$ heredando a las futuras generaciones las escasas riquezas naturales que van quedando.

Precisamente muchos de los conflictos socioambientales de nuestros días, se generan en torno a la erosión de los recursos, la concentración de los derechos de uso y la disposición sobre estos. Estos procesos de concentración tienen efectos inmediatos sobre los derechos de uso, el acceso por parte de toda la población $y$ sobre su sobrevivencia $y$ la herencia natural y sociocultural. Por ello es fundamental, no permitir la propiedad de dominio absoluto por parte de individuos sobre los bienes comunes y más bien, determinar hasta dónde se limitan o amplían los derechos de disposición sobre los recursos naturales en un determinado régimen de propiedad, en otras palabras, redefinir los límites del dominio de los bienes comunes.

Una realidad que refleja muy concretamente lo mencionado anteriormente, son 
los conflictos socioambientales vinculados al acceso y la contaminación del agua en la provincia de Guanacaste, Costa Rica. Tal y como lo muestra la investigación realizada por Alonso Ramírez Cover:

... [estos son más] expresión de problemáticas socioeconómicas y políticas vinculadas a la manifestación regional de las pautas sociales establecidas por el proyecto hegemónico neoliberal en Costa Rica. ...no se dice que no existan problemas vinculados a la disponibilidad $y$ la demanda de recursos hídricos en la zona, lo que se dice es que estos son sólo en parte responsables de la conflictividad presente; ésta es el resultado de procesos y problemáticas que son socioeconómicas y políticas en origen (2010: 10-11).

¿A qué se refiere Ramírez con el proyecto hegemónico neoliberal en Costa Rica? Precisamente, la provincia de Guanacaste, para el año 2000, pasó de ser una región caracterizada por una economía agropecuaria a una fundamentada en la comercialización de servicios.

Se trata de cadenas de producción muy asimétricas donde, al margen de muchos involucrados, existen únicamente unos pocos y muy fuertes productores y compradores. ...la gran empresa en el turismo, corren con pocos riesgos y obtienen un margen mayor de ganancias (Ramírez, 2010: 55-56) [sin contemplar las implicaciones sociales, culturales, ambientales $y$ políticas que hay detrás de este tipo de práctica].

Concretamente este proyecto neoliberal se plasma en el caso del agua de la siguiente forma:

Por un lado existe una demanda mayor de agua para usos relacionados con la generación de ganancias y la acumulación de capital. Por otro lado, existe también una presión creciente generada por otros usos, algunos previos a las acti- vidades que hoy generan ganancias. Esto deriva en tensiones socio-espaciales que proliferan y que se expresan en conflictos sobre la extracción, distribución y uso del agua... En Costa Rica, la formalización de un apartado legal concreto que lidie sobre las relaciones sociales vinculadas al acceso, uso y disposición de los recursos hídricos, es una tarea pendiente (Ramírez, 2010: 75).

La elaboración de una ley general en la materia del agua que ofrezca alguna coherencia a este subsector está pendiente.

El peligro inmediato que se presenta en Costa Rica, es la posibilidad de la privatización del agua, tal y como ha ocurrido en otros países del mundo. Según estudios, en la mayoría de estos casos, las empresas embotelladoras de agua pagan muy poco o nada por el agua que extraen, a costa de las necesidades de las comunidades, siendo estas empresas apoyadas por los gobiernos, lucran abiertamente con el patrimonio común de recursos hídricos locales. En Costa Rica, cada vez más, el Estado está en función de los requerimientos de dotar al capital de las condiciones de producción necesarias.

Otros ejemplos que lamentablemente se viven en Costa Rica, son los conflictos socioambientales vinculados a la explotación de la minería a cielo abierto y la contaminación de las plantaciones de la piña. En ambos casos, están en peligro la sobrevivencia de las comunidades y la reproducción de los recursos naturales para las nuevas generaciones. Se está de acuerdo con Ramírez cuando concluye que "los conflictos socioambientales son luchas entre los que tienen capacidades políticas y económicas para aprovecharse de los recursos y los que no. Pero así como existen estas desigualdades ambientales no están desvinculadas de otras económicas y sociales" (2010: 99).

Lo que se cree, en contraposición con esta dinámica neoliberal, es que la propuesta de los bienes comunes, como lo plantea Silke Helfrich, empieza a ver la actividad económica de una manera más integral, a reconocer los factores sociales, ambientales y ético-morales que subsidian la actividad normal de los mercados. Los 
bienes comunes posibilitan la creación de redes sociales que permitan sociabilizar experiencias de diferentes países, principalmente de América Latina, en donde, como señala Helfrich, "los cambios solamente se logran a través de duros conflictos y no meramente con buenos argumentos" (2008: 306).

De lo que se trata es privilegiar estructuras y sistemas de posesión colectiva, que permitan abstraerse de la dicotomía público-privado $y$ desplazarse hacia los derechos de propiedad, obligaciones, libertades y responsabilidades de las comunidades, frente a los bienes comunes. Los bienes comunes dirigen la mirada hacia el vínculo entre un nosotros y nosotras $y$ nuestra herencia colectiva; se refiere a la autoridad de la correspondiente comunidad de disponer de los recursos comunes, en esta generación y en las futuras.

El derecho a soñar permite desear y luchar por una sociedad libre de dominio, democrática y sobre todo, solidaria.

\section{REFERENCIAS BIBLIOGRÁFICAS}

Barlow, Maude. Oro azul: las multinacionales y el robo organizado de agua en el mundo. Barcelona: Paídos, 2004.

Barnes, P. Capitalism 3.0: a guide to reclaiming the commons. San Francisco: BerrettKoehler Publishers, 2006.

Berkes, F. Common property resources: ecology and community-based sustainable development. Santander: Ediciones Provincial, 1989.

Berkes, F. "Commons in a multi-level world". International Journal of the Commons 1. Enero 2008: 1-6.

Brand, U. "La convergencia de movimientos: los bienes comunes en tanto que cosmovisión crítica emancipatoria y en tanto que perspectiva estratégica". S. Helfrich (comp.). Genes, bytes $y$ emisiones: bienes comunes $y$ ciudadanía. México. Ediciones Böll, 2008: 302-310.

Bollier, D. Public assets, private profits: reclaiming the american commons in an age of market enclosure. Washington: New America Foundation, 2001.
Bollier, D. Is the common a movement? Trabajo presentado en The Wizards of os3: The Future of the Digital Commons. Berlín. Junio 2004.

Bollier, D. "Los bienes comunes: un sector soslayado de la creación de riqueza". S. Helfrich (comp.). Genes, bytes y emisiones: bienes comunes y ciudadanía. México. Ediciones Böll, 2008a: 30-41.

Bollier, D. Viral spiral: how the commoners built a digital republic of their own. New York: The New Press, 2008b.

Eythorsson, E. Theory and practice of itq's in Iceland: privatization of common fisheries resources. Trabajo presentado en Fifth Common Property Conference. Noruega. Mayo 1995.

Flórez, M. "¿Lo público?, ¿Lo común?, o lo nuestro, lo de todos!". S. Helfrich (comp.). Genes, bytes y emisiones: bienes comunes y ciudadanía. México. Ediciones Böll, 2008: 109-114.

Galaz, V. Privatizing the commons-natural resources, equity and the chilean water market. Chile: FLACSO, 2003.

Galaz, V. Power in the commons: the politics of water management institutions in Sweden and Chile. Suecia: Gotenborg University, 2005.

Hanna, S. Property rights in a social and ecological context: case studies and design applications. Washington: World Bank, 1995.

Hees, C. The knowledgecCommons: theory and collective action; or kollektive aktionismus? Trabajo presentado en The Wizards of 0s3: The Future of the Digital Commons. Berlín. Junio 2004.

Helfrich, S. "Commons: ámbitos o bienes comunes, procomún o 'lo nuestro". S. Helfrich (comp.). Genes, bytes y emisiones: bienes comunes y ciudadanía. México. Ediciones Böll, 2008: 42-48.

Helfrich, S. y Hass, J. "Genes, bytes y emisiones: acerca del significado estratégico del debate de los bienes comunes". S. Helfrich (comp.). Genes, bytes y emisiones: bienes comunes y ciudadanía. México. Ediciones Böll, 2008: 311-328. 
Lindayati, R. The role of macro-political economic systems in CPR. Trabajo presentando en the Eighth Biennial Conference of the International Association for the Study of Common Property. Indiana, Estados Unidos. Junio 2000.

Ostrom, E. Principios de diseño y amenazas a las organizaciones sustentables que administran recursos comunes. Trabajo presentando en De Cara a la Globalización: Organizaciones Económicas en América Latina en el Caribe. Indiana, Estados Unidos. Marzo 1999.

Ostrom, E. El gobierno de los bienes comunes: la evolución de las instituciones de acción colectiva. México: Fondo de Cultura Económica, 2000.

Ostrom, E. y Dolsak, N. The commons in the new millennium: challenges and adaptation. Massachussets: MIT Press, 2003.

Ostrom, E. et ál. (comp.). The drama of the commons. Washington: The National Academies, 2002.

Pérez, A. Los derechos ciudadanos y la defensa de los comunes en América Latina. Trabajo presentado en Conferencia Internacional sobre Comunes $y$ Ciudadanía: ciudadanía, elemento clave para el manejo sustentable de los comunes. México. Diciembre 2006.

Ramírez, A. "Conflictos socioambientales y recursos hídricos en Guanacaste; una descripción desde el cambio en el estilo de desarrollo (1997-2006)". Anuario de Estudios Centroamericanos 33-34. Costa Rica, 2007-2008: 359-385.

Ramírez, A. La gota que derramo el vaso: caracterización del desarrollo y de la conflictividad socio-ambiental vinculada a los recursos hídricos en Guanacaste. [Inédito]. 2010.

Robbins, P. Political ecology: a critical introduction. Inglaterra: Blackwell, 2004.

Schlager, E. "Common-pool resource theory". R. Durant, D. Fiorino y R. O'Leary (eds.). Environmental Governance
Reconsidered: challenges, choices, and opportunities. Massachussets. MIT Press, 2003: 145-175.

Yandle, T. y Dewees, C. "Consolidation in an individual transferable quota regime: lessons from New Zealand, 1986-1999". Enviromental management 41. Marzo 2007: 915-928.

\section{REFERENCIAS ELECTRÓNICAS}

Barlow, Maude. El agua nuestro bien común: hacia una nueva narrativa del agua. 2008. En: <http://www.boelllatinoamerica.org/downloads/water_ commons-ES-2.pdf> [consultado el 14 de marzo de 2010].

Benkler, Y. La economía política del procomún. 2003. En: <http://biblioweb.sindominio. net/telematica/yochai.html> [consultado el 26 de febrero de 2010].

Bollier, D. "The rediscovery of the commons". Upgrade IV (3). Junio 2003: 10-12. En: <http://dlc.dlib.indiana.edu/dlc/ bitstream/handle/10535/4979/up 4 3 Bollier.pdf? sequence $=1>$ [consultado el 13 de marzo de 2010].

Boyle, J. "El segundo movimiento de cercamiento y la construcción del dominio público". Law and contemporany problems 66. 2003. En: $<$ http://www.law.duke.edu/shell/cite.pl?6 $6+$ Law $+\&+$ Contemp.+Probs.+33+\%28Wi nterSpring $+2003 \% 29>$ [consultado el 13 de marzo de 2010].

Bromley, D. y Cochrane, C. "Understanding the global commons". Working paper 13. Agencia EPAT/MUCIA Research \& Training, University of Wisconsin, Madison, WI. 1994. En: <http://dlc.dlib.indiana.edu/ dlc/bitstream/handle/10535/5079/em13. pdf? sequence $=1>$ [consultado el 24 de febrero de 2010].

Cox, M. "Balancing accuracy and meaning in common-pool resource theory". Ecology and Society 13 (2). 2008. En: <http://www. ecologyandsociety.org/vol13/iss2/art44/> [consultado el 13 de marzo de 2010].

Esteva, G. Commons: más allá de los conceptos del bien, derecho humano y propiedad. 
Entrevista realizada por A. Becker. México, 2007. En: <http://www.boelllatinoamerica.org/download_es/EV_ Esteva_Final.pdf> [consultado el 13 de marzo de 2010].

Ostrom, E. "Reformulating the commons". Ambientes \& Sociedades 10. Setiembre 2002. En: <http://dlc.dlib.indiana.edu/ dlc/bitstream/handle/10535/3506/16883. pdf? sequence $=1>$ [consultado el 13 de marzo de 2010].

Ostrom, E. et ál. "Revisiting the commons: local lessons, global challenges". Sciences 5412. Abril 1999: 278-282. En: <http://www.sciencemag.org/ cgi/content/abstract/284/5412/278> [consultado el 15 de marzo de 2010].

Sánchez, D. Recreaciones, cuidados, entornos y espacios locales para la humanidad. En torno a lo común y lo público en perspectiva de derechos humanos. 2009. En: <http://pensamientocritico.info/ articulos/otros-autores/214-recreacionescuidados-entornos-y-espacios-localespara-la-humanidad-en-torno-a-locomun-y-lo-publico-en-perspectiva-dederechos-humanos.html> [consultado en octubre de 2010].

Schlager, E. y Ostrom, E. "Common property, communal property, and natural resources: a conceptual analysis". Working paper 87 (13). Indiana University: Agencia Workshop in Political Theory and Policy Analysis, 1987. En: <http://dlc.dlib.indiana.edu/dlc/ bitstream/handle/10535/3862/Schlager_ and_Ostrom-common_property_ communal_property_and_natural_ resources_a_conceptual_analysis. pdf?equence $=1>$ [consultado el 13 de marzo de 2010].

Vercelli, A. Aprender la libertad: el diseño del entorno educativo y la producción colaborativa de los contenidos básicos comunes. 2006. En: <http:// $w w w$. aprenderlalibertad. org/ aprenderlalibertad.pdf $>$ [consultado el 8 de febrero de 2010].

Vercelli, A. Repensando los bienes intelectuales comunes: análisis socio-técnico sobre el proceso de co-construcción entre las regulaciones de derecho de autor $y$ derecho de copia y las tecnologías digitales para su gestión. 2009. En: $<$ http://www.arielvercelli.org/ rlbic.pdf> [consultado el 8 de febrero de 2010].

Fecha de ingreso: 22/11/2010

Fecha de aprobación: 19/05/2011 
